\title{
Gestão da Comunicação de Crise: A Reputação Organizacional'
}

\author{
Susana Pinto ${ }^{2}$ \\ 1 Palestra proferida por ocasião do II Seminário Interistitucional de Pesquisa, realizado em 16 de maio pela Uni- \\ versidade de Taubaté , em parceria com o UNIS (Centro Univeritário do Sul de Minas). \\ ${ }^{2}$ Professora Convidada no ISCAP - Instituto de Contabilidade e Administração do Porto na área de Comunicação \\ Organizacional, com os cursos de Relações Públicas, Comunicações de Marketing e Comunicação Organizacional. \\ Também é responsável pelo Gabinete de Comunicação e R.P. do mesmo instituto. \\ É pesquisadora do CICE - Centro de Investigação em Comunicação e Educação
}


Nos dias de hoje, a definição da estratégia de comunicação integrada é fundamental para o processo de diferenciação de uma organização num mercado específico.

Atualmente, a preocupação da organização não se baseia na satisfação de necessidades através da produção / comercialização de produtos e serviços. O segredo empresarial consiste no estabelecimento de uma relação emocional, o sentir "Paixão" pela marca. Cabe à organização definir e caracterizar os seus diferentes públicos institucionais, criar comunidades, criar envolvimento, estabelecer diálogos, manter relacionamentos sólidos e eficientes, estando presente em todos os momentos da sua vida.

Com a massificação da Internet, as empresas tiveram que repensar os seus modelos de negócio e a sua atitude. Assim, uma empresa não está só a vender um produto, mas sim uma experiência; tendo uma presença na Internet, é uma empresa global; com desenvolvimento das redes sociais e dos blogs, a empresa dialoga com o seu cliente, existindo uma troca de conhecimentos e de experiências; uma empresa deve ter uma atitude proactiva, diferenciar-se em relação à concorrência, criando um culto do produto e da própria marca. Pretende-se a criação da evangelização da marca.

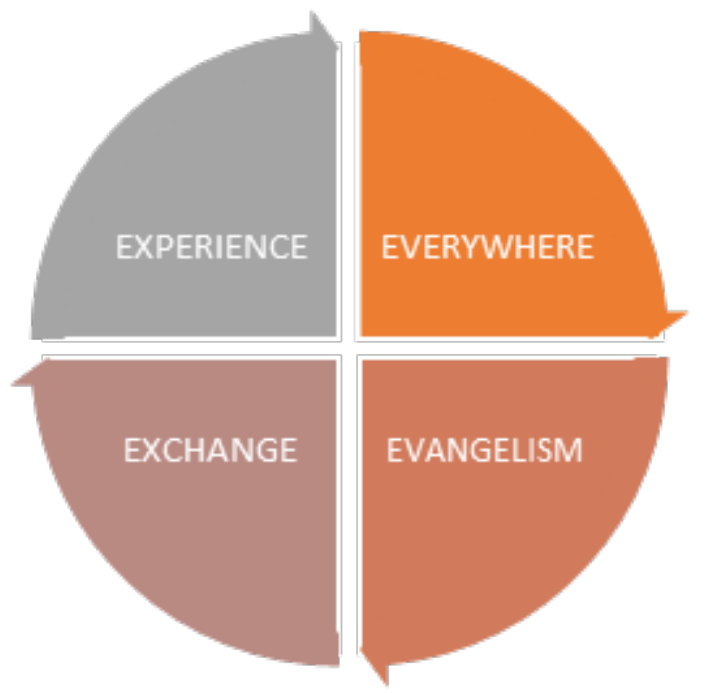

Figura 1 - 4 E's - Fonte: Esquema adaptado de acordo com a entrevista a (Fetherstonhaugh, 2010), à Revista Marketeer (2010)

O grande desafio das organizações consiste em gerir múltiplos canais e diferentes meios de comunicação, a definição de uma estratégia de b-communication (blended communication), ou seja, comunicação integrada numa perspetiva on-line e off-line. É fundamental estabelecer diálogos com os seus diferentes públicos, criar interações, avaliar reviews, a criação de conteúdos diferenciadores, criativos e com objetivo de criação de valor, pesquisar e avaliar o "feedback" dos clientes e potenciais, meios de comunicação social, líderes de opinião, etc..

O consumidor está rodeado de marcas, de diferentes apelos e estímulos emocionais e racionais. Assim, como procede à escolha de uma determinada marca em detrimento de outra?

Os fatores são variados como, por exemplo, a experiência e vivência com a marca, os estilos de vida, os diferentes grupos sociais em que estamos inseridos, a satisfação das expectativas e interesses entre um público e a organização, a perceção e a reputação organizacional. 


\section{Reputação organizacional}

A reputação organizacional é um ativo intangível que merece bastante atenção, uma vez que, é a soma de dois fatores, a perceção e valores organizacionais, que têm por base a história da empresa, suas aspirações e visão relativamente ao futuro. A reputação incorpora aspetos positivos e negativos, permitindo a criação de valor e a vantagem competitiva para a empresa. A reputação organizacional deriva de vários fatores: a confiança do público, a perceção, a popularidade, o poder da marca, o sentimento de cuidar, a estratégia de posicionamento que a diferencia das outras marcas, tornando-a única, especial e credível.

A reputação não se "fabrica", conquista-se. De acordo com Benjamim Franklin "A porcelana e a reputação danificam-se com facilidade nunca se podendo reparar completamente".

Tendo por base a afirmação de Benjamim Franklin, as instituições devem gerir a sua reputação com o objetivo de se diferenciar da concorrência, evitando e prevenindo eventuais situações de crise. Uma situação de crise é um acontecimento, uma revelação de informação, uma acusação ou um conjunto de circunstâncias que ameaçam a integridade, o prestígio ou a sobrevivência de uma organização. Um crise não sendo tratada a tempo, poderá causar um enorme impacto negativo na instituição. Por outro lado, com a proliferação das redes sociais, blogs, fóruns de opinião um "evento" é disseminado em poucos minutos, numa escala mundial. Considerando este cenário é essencial a criação de um plano de comunicação de crise que envolva toda a instituição e defina a estratégia de interação / comunicação com todos os públicos institucionais.

A questão que se coloca é: quantas instituições de ensino superior - público ou privado - têm planos de gestão de comunicação de crise?

A seguir apresento duas situações que aconteceram, no período de 2014 e 2016, na cidade do Porto (Portugal) que envolveram duas instituições do ensino superior.

\section{CASO DE ESTUDO}

Em maio de 2014, um grupo de jovens lança o "pânico" na Polo Universitário da Asprela, assaltando e agredindo vários estudantes junto ao Instituto Superior de Contabilidade e Administração do Porto (ISCAP) e a Faculdade de Engenharia da Universidade do Porto (FEUP).

Um grupo de jovens estudantes da FEUP decidiu contra-atacar os assaltantes que tinham aterrorizado os estudantes do Pólo. Segundo o jornal português "Sol», para identificar os vários assaltantes, alguns estudantes criaram a página de Facebook, "Gunas da Areosa» onde colocaram as fotografias dos suspeitos, e conceberam uma aplicação para telemóvel, a "Guna-Alert», com ligação direta à polícia. Os estudantes terão, ainda, entrado nas contas de Facebook dos suspeitos, após descobrirem as palavra-passe, e terão, até, enviado mensagens falsas para os despistar. 


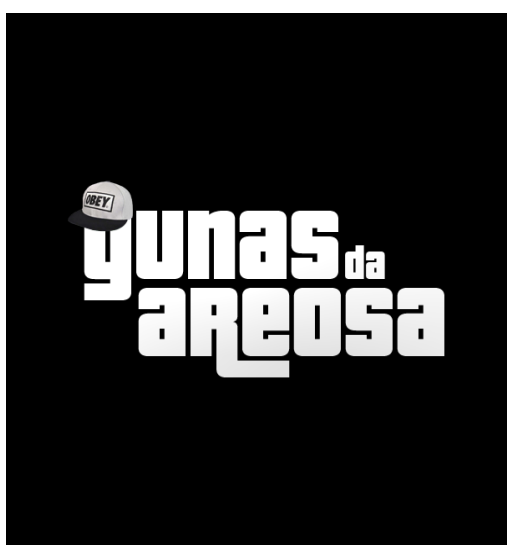

Figura 2 - Logótipo do facebook "Gunas da Areosa"

Em apenas uma semana esta página atinge os 25 mil "likes" e promoveu uma troca de mensagens entre os estudantes. Por outro lado, promoveu a uma situação de entreajuda entre a comunidade estudantil, criando-se movimentos para que ninguém circulasse sozinho, combinavam pontos de encontro.

As instituições, ISCAP e FEUP, apareceram nos principais meios de comunicação social, não sendo um fator positivo para a imagem organizacional e sua reputação. A comunicação das duas instituições com a polícia de segurança pública e com as entidades governamentais permitiram que o caso fosse resolvido com alguma rapidez. Este caso demonstra o enorme poder das redes sociais, tendo sempre em atenção cenários positivos e negativos. Hoje em dia, a gestão das redes sociais e do feedback é fundamental, devendo ser gerida "ao minuto". A noção de tempo e de reação no mundo digital é diferente, uma hora, um dia, 48 horas é demasiado tempo para se solucionar uma situação de crise. Esta situação poderia ter contornos mais graves pois a criação da página de facebook poderia ter gerado mais violência e as instituições de ensino superior perderiam o controlo total da história. Por outro lado, permitiu criar laços e uma solidariedade nunca antes vista entre a comunidade escolar e o início de um projeto que permitiu a criação de sinergias e trabalho conjunto entre as várias instituições do Pólo Universitário da Asprela.

\section{ASPRELA INNOVATION DISTRICT}

O Asprela Innovation District (AID) é um espaço vibrante de conhecimento aplicado, em que espaços públicos e privados interagem em redes de colaboração inovadoras criando valor para a sociedade. Com o objetivo único, incontornável e insubstituível da agregação institucional, o Asprela Innovation District é um projeto de divulgação académica, científica, cultural e social do Pólo da Asprela. 


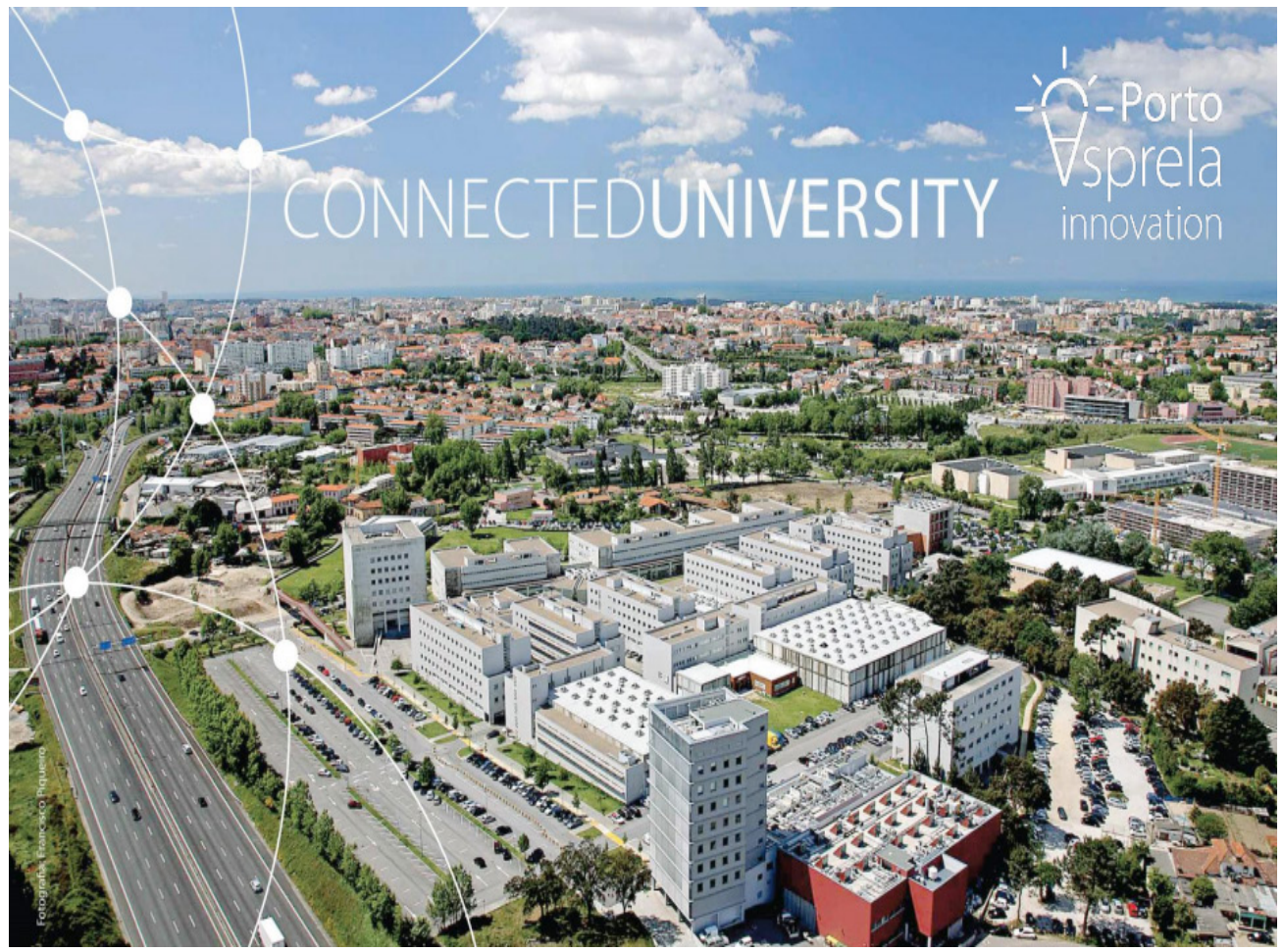

Figura 3 - Asprela Innovation District

Hoje, o pólo universitário da Asprela representa uma das maiores concentrações de talento, conhecimento e inovação na Europa. De facto, em pouco mais de um quilómetro quadrado trabalham mais de 14.000 pessoas, na maioria com habilitações superiores e em funções de grande complexidade. O pólo acoIhe também cerca de 38.000 estudantes e lança no mercado mais de 10.000 graduados por ano, o que corresponde em ambos os casos a cerca de um terço do total regional. Acrescem ainda os inúmeros visitantes externos: investigadores, conferencistas, clientes empresariais e utentes dos hospitais. O pólo universitário da Asprela é caracterizado por uma distribuição equilibrada de recursos entre as áreas de ciências da saúde e da vida, ciências exatas e tecnologias, e ciências económicas e sociais, o que potencia uma abordagem multi-disciplinar aos desafios complexos do nosso tempo. O pólo estruturou-se em redor do Hospital Escolar de S.João que, juntamente com o Instituto Português de Oncologia do Porto, concentra cerca de metade dos profissionais que aqui trabalham e que asseguram anualmente cerca de 1,5 milhões de consultas ou intervenções médicas. Nas proximidades, situa-se também o Centro Hospitalar Conde de Ferreira, da Santa Casa da Misericórdia do Porto, unidade de referência na área da saúde mental. Mais de 1300 investigadores, sendo metade docentes universitários, integram 26 unidades de I\&D reconhecidas pela Fundação para a Ciência e a Tecnologia. Estas unidades captaram em 2015 mais de $70 \mathrm{M} €$ em financiamento base e competitivo de investigação. Destacam-se na última avaliação, com classificação excecional o CONSTRUCT (engenharia civil) e o i3S (saúde), e com classificação excelente o LEPABE e o LSRE-LCM (ambos em engenharia química) e o INESC TEC (engenharia de sistemas e computadores). O AID acolhe também o instituto INEGI em engenharia mecânica e industrial, com participação empresarial, e um centro Fraunhofer na área das soluções de informação e comunicação assistiva. Dados obtidos no Web of Science mostram que o pólo é responsável por mais de $20 \%$ das publicações científicas nacionais, afirmando-se como o local de maior produção de conhecimento do país. Destacam-se as ciências exatas e tecnologias, particularmente nas áreas de engenharia química, mecânica, civil, materiais, eletrotécnica e informática. E as áreas de saúde e da vida, nomeadamente nas áreas das neurociências, farmacologia, oncologia, biologia molecular, saúde pública, tecnologia alimentar e ambiente. No pólo tecnológico do Parque de Ciência e Tecnologia (UPTEC TECH) trabalham atualmente 
mais de 1200 pessoas, em cerca de 40 centros de inovação empresariais (muitos internacionais) e empresas âncora, e em mais de 70 startups em incubação, que beneficiam da proximidade com a academia e a produção do conhecimento. O AID atrai também outras empresas para as suas proximidades, de que são exemplo a Sonae BIT, na área dos sistemas de informação para o retalho, e a WebHelp, uma das maiores empresas globais de outsourcing de processos, instalada no parque empresarial Hipercentro, juntamente com outras 40 empresas.

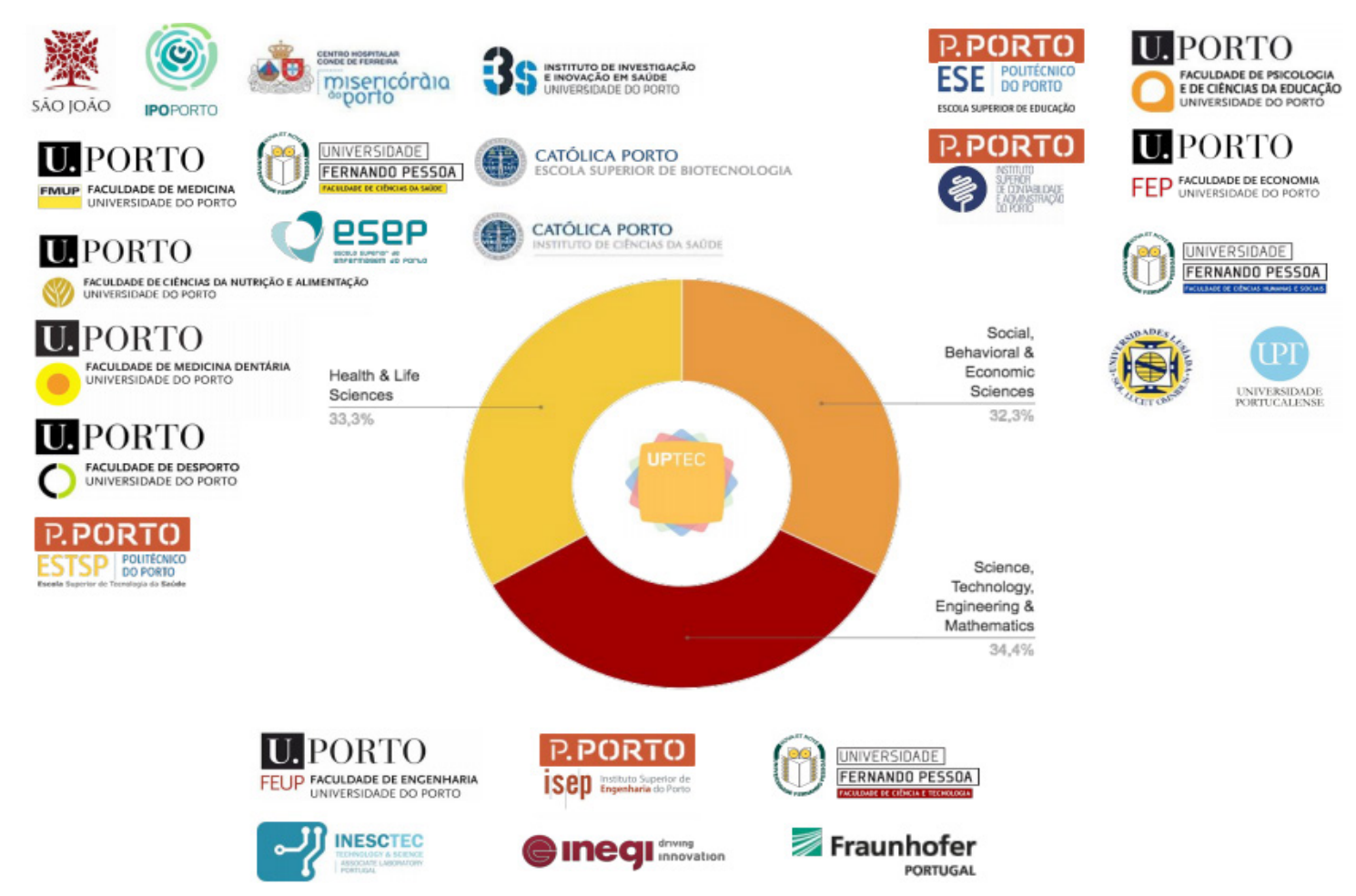

Figura 4 - Caracterização do AID

O grande desafio para o futuro é pois nutrir esta comunidade dinâmica, derrubando os muros que artificialmente a impedem de explorar todo o seu potencial e expandindo e qualificando o espaço público para que todos possam aqui exercer o seu direito de cidadania e fruir de qualidade de vida. Um ecossistema sustentável, com impacto social e afirmação internacional: o Asprela Innovation District.

A criação do Asprela Innovation District permitiu que todos os gabinetes de comunicação deste Pólo começassem a interagir, a partilhar experiências e conhecimento. Foram criados canais de comunicação, comissões de trabalho (organização de eventos, comunicação de crise, responsabilidade social, marca, etc.) e definidas metodologias de trabalho.

Em abril de 2016, a FEUP e o ISCAP voltam a estar sob o olhar da comunicação social. Um estudante do ISCAP faleceu nas instalações da FEUP, devido a um desentendimento. A FEUP, ao início da manhã fez uma conferência de imprensa, explicando os factos que sucederam durante a madrugada. A principal preocupação da Presidência do ISCAP foi a situação familiar e o apoio imediato aos familiares e a proteção da vida pessoal da vítima e sua família, deslocando-se ao lar da família. Do ponto de vista de comunicação interna, 
havia um porta-voz dando a informação atualizada à comunidade escolar através de um envio de comunicado. Para evitar especulações marcou-se uma conferência de imprensa em que o Presidente do ISCAP falou com todos os meios de comunicação social. Por norma, cabe à organização proteger a imagem do Presidente mas, considerando os fatores "emocional e humano" considerou-se que mostraria respeito pela família e estudantes do ISCAP. A evolução da notícia durante o dia, alterando de uma situação de homicídio para acidente. Esta situação de crise estava concluída ao fim de 24 horas.

Neste caso específico, durante todo o dia, os gabinetes de comunicação das duas instituições efetuaram diversos contactos entre si, partilharam informações e definiram estratégias de atuação. Por outro lado, desde o início do Asprela Innovation District partilhamos boas práticas e tivemos sessões de formação que permitiram estruturar um plano de gestão de comunicação de crise.

Este cenário só foi possível pois a nossa visão sobre a comunicação é integrada, baseando-se na partiIha e partindo do princípio que juntos iremos mais longe e o caminho será mais fácil. 